\title{
EXPLICACIONES NO PSICOLOGICAS DEL COMPORTAMIENTO
}

\author{
Stanley Schachter
}

Hubo un tiempo en que a los estudiantes licenciados en psicología clínica de la Universidad de Minnesota se les exigía hacer un curso de neuroanatomía. Como este curso estaba destinado a estudiantes de fisiología, generalmente los psicólogos lo encontraban algo difícil; se quejaron suspiraron y lamentaron, pero les gustara o no, generaciones de clínicos de Minnesota cursaron ese año de neuroanatomía. Ya que Minnesota por aquella época era conocida por sus trabajos en psicometría clínica y estaba más que interesada en los principios de la psicología operante y la caja negra de Skinner, yo, como miembro nuevo de la facultad, nunca entendí muy bien a qué venía tanto jäleo. Por fin decidí que Paul Meehl y Stark Hathaway, por aquél entonces líderes intelectuales del ala clínica del departamento, sospechaban que algún día ellos y los de su ralea serían exterminados por algún bioquímico maloliente, ya que iba a resultar que la esquizofrenia, y la neurosis de ansiedad y la paranoia y similares, no tenían nada que ver con Mamá o con ambientes empobrecidos o con complejidades psicodinámicas de ningún tipo, sino que eran debidas al exceso o defecto de alguna sustancia química de impronunciable nombre en algún rincón inaccesible del cerebro. Y sospecho que Meehl y Hathaway querían simplemente asegurarse de que sus estudiantes pudieran al menos entender qué era lo que les había exterminado incluso si no podían hacer nada al respecto.

Las inseguridades de los clínicos de Minnesota destacan una de las peculiaridades del campo. El objeto de estudio del psicólogo, más aún del científico social, es una máquina - una máquina biológica hecha de tripas, glándulas y fluídos- pero, en conjunto, las teorías y conceptos explicativos del científico social no tienen casi nada que ver con dicha maquinaria. En muchas, quizá en la mayoría de las áreas de interés para los científicos sociales, así es como debe ser. Dado el estado actual del conocimiento biológico, sería pretencioso y ridículo intentar una explicación biológica de una preferencia política o de una opción sociométrica, o de las razones de la superioridad de los grupos estructurados cooperativamente sobre los estructurados competitivamente. He observado, sin embargo, que en muchas áreas estamos mucho más cerca de un reduccionismo útil de lo que la mayoría de los científicos sociales sospechan, y apuntaría que el crecimiento del conocimiento tanto de las ciencias biológicas como sociales ha sido tal en décadas recientes, que en algunas de las áreas más sorprendentes el conocimiento biológico es ya capaz de revolucionar nuestra comprensión de la naturaleza de un fenómeno presumiblemente psicológico o social.

*Reproducido con autorización del autor. Traducción de Susana Rubio Swift. 
Intentaré documentar esta discusión presentando tres casos de la historia reciente de la ciencia social - uno recogido de la psicología médica, otro de la antropología y otro de la psicología social experimental, en los que los datos son tales que se puede examinar el poder relativo de las explicaciones sociopsicológicas versus biológicas de un fenómeno.

He escogido primero la psicologia médica, el campo que más afectaba a los clínicos de Minnesota por una muy buena razón. Las enfermedades que en algún momento de la historia médica se han considerado de etiologia psicológica, incluyen no sólo antiguos clásicos psicosomáticos como asma, úlceras, colitis, neurodermatitis, dismenorrea y similares, sino, sorprendentemente, también enfermedades como la enfermedad de Parkinson, sifilis en su fase terciaria y tuberculosis.

\section{El síndrome de Gilles de la Tourette}

Para ilustrar la acción reciproca de las explicaciones psicológicas y biológicas en la medicina psicológica, revisaré la historia reciente de una enfermedad exótica conocida como síndrome de Gilles de la Tourette. Escojo esta enfermedad en concreto porque la literatura al respecto es fácilmente accesible pero lo suficientemente limitada como para que uno sienta la seguridad de que ha repasado la literatura y tiene un esquema razonablemente preciso del estado actual del asunto.

El síndrome de Tourette es un estado caracterizado por múltiples tics, tanto físicos como vocales. Físicamente casi cualquier parte del cuerpo puede estar involucrada tanto en tics simples como un guiño de ojos o nariz, como en tics de movimientos complejos como saltar, ponerse en cuclillas, dar patadas, arrodillarse y similares. Vocalmente, el estado se caracteriza por cualquier combinación de síntomas tales como gruñidos, silbidos, ladridos y lo más extraño de todo, tics tales como ecolalia - repetición involuntaria de las palabras de otros- y coprolalia - repetición compulsiva de palabras obscenas-.

Esta enfermedad es una dolencia en transición. En tiempos se consideraba el síndrome Tourette un estado psicológico, provocado por desórdenes psicológicos y tratable con psicoanálisis o terapia de conducta de uno u otro tipo. Más recientemente, la presión de la investigación ha hecho que la interpretación psicológica de la enfermedad sea menos y menos plausible, y parece ser cada vez más evidente que la dolencia es puramente de origen bioquímico o biológico. El caso está lejos de cerrarse, pero la tendencia de los datos es tal que parece inevitable que se vaya a probar que Tourette es de origen biológico, tal como se considera ahora que la enfermedad de Parkinson, la tuberculosis y la sífilis en su fase terciaria están determinadas biológicamente.

En mi descripción de esta enfermedad, me baso principalmente en el estupendo libro sobre la materia de Shapiro, Shapiro, Bruun y Sweet (1978).

Históricamente Charcot designó a este estado con el nombre de Georges Gilles de la Tourette, quien en 1894 y 1895 describió a nueve pacientes con múltiples tics verbales y físicos. Aunque la medicina psicológica había estado interesada durante mucho tiempo en tics y movimientos compulsivos, fue el escrito de Ferenczi (1921), el que disparó lo que Shapiro et al. identifican como el periodo psicoanalítico de la historia del síndrome Tourette - un período que fue desde 1921 hasta casi 1955, cuando se escogió un tratamiento a base de drogas más que de psicoterapia para tratar el estado. Fereczi sugirió que los tics pueden ser los "equivalentes esterotipados del onanismo y que la notable conexión de los tics con la coprofalia... podrían no ser más que la expresión verbalizada de la misma emoción erótica que suele manifestarse por medio de movimientos simbólicos"' (p.I.).

Abraham (1927), no estando de acuerdo, hipotetizó que los tics son de origen sádi- 
coanal más que de origen erótico y sugirió que: "El tic que toma la forma de hacer muecas tiene un obvio sentido hostil... Otros tics, en concreto la coprolalia muestran sus orígenes anales bastante claramente... algunos, por ejemplo, el tic del silbido, están directamente derivados de procesos anales (flato). Aquí el paciente lleva a cabo sus propósitos hostiles y degradantes por medios anales" (p. 234).

Esta oposición teoríca provocó una avalancha de observaciones y teorías en conflicto, que se resumen en Shapiro et al. (1978) como identificadores variados de la etiologia de los tics de Tourette como "... estados orales, anales, genitales, narcisistas, obsesivo-compulsivos, psicóticos, agresivos, histéricos, u otros estados psicológicos inconscientes, peyorativos" (p. 63). No hay necesidad de ir más allá. La cuestión es que durante al menos un periodo de treínta y cinco años, el sindrome Tourette se consideraba casi exclusivamente una enfermedad psicológicamente inducida y la principal discusión sobre el estado consistía en la naturaleza de la causa psicológica.

Probablemente fueron el fracaso constante de cualquier forma de psicoterapia o terapia de conducta, más las primeras indicaciones de que las fenotiacinas podrían aliviar el desorden, las que llevaron a la creciente sospecha de que la naturaleza del desorden era más orgánica que psicológica. Cualquiera que sea la causa, es probablemente razonable evaluar las interpretaciones actuales de este desorden como mucho más biológicas que en cualquier otro tiempo anterior de la historia de la medicina. Esta evaluación se basa en los hechos siguientes:

1. Baterías de tests psicológicos que incluyen el WAIS o el WISC, Bender-Gestalt, Roscharch, Test de Dibujo de Persona, TAT, y MMPI han fracaso al intentar encontrar en pacientes con síndrome Tourette alguna indicación de "esquizofrenia, psicosis sub. yacente, inhibición de la agresión, rasgos obseșivo-compulsivos, histeria, somatización, hipocondriasis u otros factores psicopatológicos comunes" que se han sugerido por un teórico u otro como causantes o acompañantes de Toureite (Shapiro et al., 1978, p. 157).

2. Los siguientes datos de Shapiro et al. proporcionan evidencia directa de la implicación orgánica. En todos los casos, los datos de los sujetos Tourette son considerable y significativamente más cuantiosos que los de los grupos control de pacientes externos psiquiátricos.

a. Se manifestan anormalidades en el EEG en el $47 \%$ de los sujetos Tourette ( $71 \%$ de niños y $25 \%$ de adultos).

b. En el test de Bander-Gelstalt, el $42 \%$ de los pacientes Tourette manifiesta signos orgánicos y el $68 \%$ recibe puntuaciones globales de organicidad en tests psicológicos.

3. La identificación de $\mathbf{1 8}$ familias con el síndrome Tourette más la frecuencia relativamente alta de tics en los pacientes de las familias de los pacientes Tourette, sugiere la existencia de un factor génetico.

4. Finalmente observamos que el estado mejora notablemente tras la administración de una droga llamada haloperidol - un bloqueador fuerte de la dopamina. Un $90 \%$ de los pacientes muestra una mejoría notable cuando toman esta droga, comparados con el aproximado $10 \%$ que mejoran con tratamiento psicológico.

Obviamente, la evidencia de una etiología orgánica del síndrome Tourette es todavia circunstancial. Hasta ahora no hay un proceso o agente orgánico identificado que haya resultado ser responsable del desorden. Dado el éxito de los agentes bloqueadores de la dopamina en el tratamiento del desorden, se ha hipotetizado que el síndrome Tourette se debe a un exceso dopaminérgico; hasta ahora, sin embargo, la investigación no ha podido apoyar esta hipótesis. No obstante, este autor opina que la presión de los datos acumulados casi implacablemente, lleva a la conclusión de que este es un estado orgánica y no psicológicamente inducido y de que es simplemente cuestión de tiempo el que la investigación identifique el agente biológico responsable. Probablemente la barrera más fuerte para aceptar esta conclusión es el extraño síntoma de la 
coprolalia, ya que parece de alguna manera particularmente imposible que pueda haber una simple base bioquimica para maldecir compulsivamente. Sin embargo, se ha demostrado que la coprolalia se da en estados orgánicos reconocidos como tales, por ejemplo en la klazomanía, secuela de la encefalitis (Benedek, 1925; Wohlfart, Ingvar y Hellberg, 1961), y ocasionalmente también en pacientes después de sufrir accidentes cerebrovasculares o en aquellos con paresia general.

\section{Diferencias étnicas en la conducta en estado de embriaguez}

Me dirijo ahora al tema de las diferencias étnicas en cuanto a la reacción al alcohol. En términos reduccionistas, esta es un área de gran interés, ya que durante mucho tiempo las ciencias biológicas y psicológicas se han articulado muy bien. Por turno, los científicos sociales han corregido la inocencia de los farmacólogos, y los biólogos han abierto nuevas posibilidades interpretativas para lo que parecían ser problemas puramente antropológicos o sociológicos. La secuencia es la siguiente:

Clásicamente, los farmacólogos han compartido la interpretación convencional de la civilización occidental sobre los efectos del alcohol. Ya en el año 50 a.C. Séneca escribió: "El alcoholismo no crea el vicio; simplemente lo expone a la vista". La versión farmacológica de esta hipótesis se puede encontrar en el tratamiento que casi cualquier antiguo libro de texto da sobre el alcoholismo. Por ejemplo, en Drill (1958) se encuentra: "El alcohol, incluso en cantidades bastantes pequeñas, provoca la pérdida de inhibición y el individuo responde a muchos impulsos que normalmente reprime" (p. 199). Naturalmente, los farmacólogos se han inclinado a pensar en los efectos del alcohol tal y como lo hacen sobre los efectos de cualquier otra droga. El alcohol es una droga que tiene una determinada serie de efectos sobre el sistema nervioso central, y esto supone un patrón concreto de comportamiento desinhibido. Tal y como Greenberg (1953) describe el proceso, "El alcohol... deprime el nivel más elevado del cerebro el centro de las inhibiciones, prohibiciones y entendimiento... el bebedor siente que es un 'ser humano libre'; muchas de sus inhibiciones normales desaparecen; se toma libertades personales y sociales en cuanto el impulso aparece" (p. 88). Tal como una inyección de norepinefrina disminuirá la tasa cardíaca, así una inyección de alcohol disminuirá la acción de aquella porción de sistema nervioso central que está involucrada en el autocontrol. Así está hecha la maquinaria biológica, y esa es la explicación de los efectos del alcohol en la especie humana.

El problema con este punto de vista es que la especie humana parece distar de la uniformidad en su reacción al alcohol. de hecho, tal y como les ha encantado señalar a los antropólogos y sociólogos, hay sociedades que manifiestan prácticamente cualquier reacción imaginable al alcohol. En base a.un estudio intercultural comprensivo de los efectos del alcohol, MacAndrew y Edgerton (1969) concluyen:

(1) Hay sociedades en las que el comportamiento en estado de embriaguez de sus miembros no exibe nada que pueda ser razonablemente descrito como desinhibido; (2) hay sociedades en las que el comportamiento en estado de embriaguez de sus miembros ha padecido notables transformaciones a lo largo del tiempo; y (3) hay sociedades en las que el comportamiento en estado de embriaguez de sus miembros es radicalmente diferente de una serie de situaciones o circunstancias socialmente definidas a otra. (p. 61)

En resumen, no existe la reacción invariable al alcohol que sugiere el tipo de formulación farmacológica. Para explicar la enorme diversidad cultural e histórica de las respuestas al alcohol, MacAndrew y Edgerton'han sugerido que el comportamiento en estado de embriaguez es aprendido e hipotetizan: 
En el curso de la socialización, las personas aprenden sobre el alcoholismo lo que su sociedad 'sabe' del alcoholismo; y aceptando y actuando sobre los conocimientos que asi les han sido enseñados, se convierten en la confirmación viva de las enseñanzas de su sociedad. (p. 88).

En el siguiente paso de la secuencia corresponde a los biólogos, quienes sin expresar explicitamente la pregunta han, de hecho, empezado a preguntar, "¿Por qué diferentes sociedades aprenden, biológicamente, cosas distintas sobre el alcohol?" Para comprender cómo se llegó a hacer este tipo de pregunta será necesario describir primero la imagen antropológica de los chinos quienes, como grupo, aparecen clásicamente, para ilustrar el punto de vista de los antropólogos de que el alcohol no tiene por que llevar. a la desinhibición. Aunque los chinos beben libremente, no parecen tener ningún problema con el alcoholismo y en general parecen reacción al alcohol con buen humor y alguna tontería, quizá, pero con prácticamente ninguna manifestación de violencia o de descarga de cualquiera de las emociones más bastas. Esta caracterización se basa en las observaciones sobre bebida de La Barre (1946) en la región de Kunming, en los datos de Lin (1953) sobre el alcoholismo en tres pueblos de Formosa y en el estudio de Barnett (1955) del comportamiento alcohólico y el alcoholismo entre los cantoneses del Barrio Chino de Nueva York. Los tres estudios presentan una imagen muy similar, mejor que parafrasear citaré directamente el resumen de Barnett de estas observaciones y de su interpretación de estos hechos:

El consumo de bebidas alcohólicas está muy extendido en el Barrio Chino de Nueva York. La embriaguez no es, sin embargo, predominante porque la actitud de la familia asi como la de la comunidad desanima su presencia. La incidencia del alcoholismo crónico es baja y el alcoholismo como problema social es relativamente poco importante.

El papel del alcohol puede entenderse a partir de un estudio del ambiente social. En conjunto las expectativas y obligaciones fundamentales de la cultura Kwantung subsisten en el Barrio Chino. Dentro del hogar y en reuniones sociales, la bebida tiene una importante función social. En comidas y banquetes la comida abundante se acompaña de una consumición considerable de alcohol. Cuando está borracho, el bebedor chino normalmente es pacífico y la borrachera pública es poco corriente y fuertemente reprobada. Puede haber una descarga de agresión que rara vez se manifiesta en violencia, sino en comportamiento y habla expansivos.

En el marco cultural del Barrio Chino está limitado el consumo del alcohol por parte de las mujeres y a una mujer borracha se le trata con más severidad que a un hombre. Existe una actitud permisiva hacia el consumo de alcohol por parte de muchachos y aprenden pronto una serie de actitudes que tolera el consumo social pero desaprueba la intoxicación.

La segunda generación muestra una aculturación considerable y hay un relajamiento general de los controles tradicionales en la familia china. En este marco se podría esperar del joven chino que mostrara una tendencia hacia el exceso en el consumo de alcohol especialmente en vista de las tensiones psicológicas de su situación entre los modos de vida americanos y chinos. Hasta ahora, sin embargo, los controles sociales parecen ser más efectivos que las fuerzas de la desorganización y la joven generación muestra pocos casos de alcoholismo. (p. 225-26)

Parece así, que el consumo de alcohol entre los chinos está muy extendido, que los chinos bajo los efectos del alcohol son generalmente pacíficos y amigables, que el alcoholismo prácticamente no existe (1) y que la actitud china hacia la bebida subsiste 
entre la segunda generación de chinos americanos a pesar de la tensión de la transición a otra cultura. Estos son los datos aparentes, y el antropólogo interpreta estos hechos en términos de "sanciones sociales contra el consumo desenfrenado del alcohol". Sin embargo, no está claro porqué estas sanciones hipotetizadas son tan fuertes y tan notablemente efectivas entre los chinos comparados con la mayoría de los grupos caucasianos. Para una posible explicación, volvamos sobre algunos raros hechos fisiológicos sobre el alcohol y los chinos.

\section{El Rubor Oriental}

Una de las observaciones más curiosas que hacen los chinos, y los orientales en general, acerca de sí mismos es que el alcohol les pone rojos observación que fue comprobada por el médico Wolff (1972), quien, mediante la densiometría óptica del lóbulo de la oreja, comparó grupos de caucasianos y orientales (taiwaneses, coreanos y japoneses). La observación es, sin duda alguna, correcta, ya que los orientales respondieron irresistiblemente a la cerveza con un sonrojo visible y un marcado incremento de la densidad óptica, mientras que la cerveza no tenía apenas ningún efecto en la coloración de la piel de los caucasianos. A continuación Wolff comparó bebés recién nacidos añadiendo unas pocas gotas de oporto a un cinco por ciento de una solución glucosa. Los bebés orientales respondieron al oporto con un marcado rubor mientras que a los bebés occidentales no les afectó, un hallazgo que sugiere que estos efectos no se deben a una dieta diferente o a una experiencia previa con el alcohol. Al comparar los informes subjetivos de sujetos adultos después de beber cerveza, los orientales tendían a informar sobre palpitaciones, taquicardia, debilidad muscular, aturdimiento, somnolencia y "estómago caliente", mientras que los sujetos caucasianos informaron de casi ninguno de estos efectos.

Ewing, Rouse y Pellizzari (1974) replicaron estos hallazgos administrando pequeñas cantidades de etanol sintético a grupos de sujetos orientales (en su mayoría chinos y japoneses) y occidentales. Encontraron resultados idénticos en cuanto a rubor e informes similares de síntomas disfóricos subjetivos. También midieron la presión sanguínea y la tasa cardíaca. Para mostrar la magnitud de estos efectos, la Tabla 1 reproduce los datos sobre là tasa cardíaca.

\begin{tabular}{lccc} 
Momento & $\begin{array}{c}\text { Latidos por min. en: } \\
\text { Grupo oriental } \\
\mathbf{( N = 2 4 )}\end{array}$ & $\begin{array}{c}\text { Grupo Occidental } \\
\mathbf{( N = 2 4 )}\end{array}$ & $\begin{array}{c}\text { Nivel de } \\
\text { significación }\end{array}$ \\
\hline & 79,0 & 78,8 & n.s. \\
Antes de la ingestión & 89,1 & 75,8 & p, 001 \\
30 min. después & 85,8 & 76,4 & p, 02 \\
60 min. después & & & \\
\hline
\end{tabular}

Fuente: De Ewing, Rouse y Pellizari, 1974.

Tabla 1. Medias de la tasa cardiaca de sujetos orientales y occidentales antes y después del consumo de pequeñas cantidades de alcohol.

(1) Según Barnett (1955), entre 1933 y 1949 hubo 17.515 arrestos registrados de chinos en el Barrio Chino de Nueva York. En ninguno de estos arrestos se especificaba la embriaguez. 
Es obvio que el alcohol tiene un impacto dramático sobre la tasa cardiaca de los sujetos orientales y poco efecto en los sujetos occidentales. Como sus sujetos vivían todos en los Estados Unidos y la mayoría tomaban una dieta occidental, Ewing et al., como Wolff, dudaron de que estas diferencias pudieran ser achacadas a la dieta. También hay una evidencia independiente posterior (Fenna, Mix, Shaefer, Gilbert, 1971; Wolff, 1973) de que estos efectos no se pueden explicar por la experiencia diferencial con el alcohol, ya que los orientales familiarizados con el alcohol son considerablemente más sensibles de lo que lo son los occidentales igualmente experimentados.

Obviamente existen diferencias mayores entre los orientales y los occidentales en los efectos fisiológicos del alcohol. Cantidades de alcohol que no tienen prácticámente ningún efecto en los occidentales producirán una serie de marcadas consecuencias fisiológicas disfóricas en los orientales. Estas diferencias existen desde el nacimiento, y no parecen ser explicables ni por la dieta ni por la experiencia diferencial con el alcohol.

Dada esta serie de hechos, puede ser innecesario evocar los elaborados conceptos de la ciencia social para comprender el comportamiento a la hora de beber de los chinos. Puede ser que los chinos sean bebedores moderados porque el exceso de alcohol les pone enfermos. Puede ser que no sean bebedores violentos porque el alcohol les pone a dormir antes de que se puedan poner violentos. Puede haber pocos alcohólicos entre los chinos porque no pueden beber lo suficiente como para llegar a ser alcohólicos, etc. Se podría, con escasa dificultad, componer un esquema en su mayor parte biológico desde el cual, sin aportaciones de la antropología o la sociología, sería probablemente posible deducir la mayoría de los hechos sobre el comportamiento de consumo alcohólico chino. Sin embargo, desgraciadamente, tal ejercicio reduccionista sería, hasta ahora, prematuro a causa de dos grupos asiáticos derivados que enredan el de otro modo tan elegante esquema. Estos grupos no son otros que los Indios Norteamericanos y los Esquimales, grupos para los que el alcoholismo y la violencia inducida por el alcohol han sido destacados problemas sociales.

Como los indios norteamericanos se clasifican normalmente como "miembros de la población Mongoloide", Wolff (1973) repitió con los indios el experimento de rubor que habia hecho con los orientales. Comparó a los miembros de una tribu de indios americanos (los Cree del Este, de la familia Algonquin) con los americanos de origen puro chino o japonés y con un grupo de caucasianos americanos. En este experimento Wolff replicó su hallazgo anterior: el alcohol provoca rubor en el grupo oriental y no en el caucasiano. En cuanto a los indios americanos, su reacción fue precisamente la misma que la del grupo oriental: el alcohol provoca un rubor. Además de las medidas densitométricas Wolff en su estudio también midió el pulso y la temperatura de las mejillas. En ambas medidas los grupos de indios y de orientales eran similares entre sí y considerablemente más reactivos que el grupo caucasiano.

Tenemos, así, dos grupos asiáticos que demuestran una sensibilidad vasomotora al alcohol, similar. Para uno de los grupos el alcohol es un gran problema social, y para el otro no es problema en absoluto. Para seguir con las complicaciones, Fenna, Mix, Schaefer y Gilbert (1971) probaron implicaciones bioquimicas sobre la observación que hizo la policía canadiense de que los indios y los esquimales encarcelados tardan mucho más tiempo en serenarse que los borrachos blancos. Administraron alcohol por vía intravenosa a grupos de varones esquimales, indios y blancos y midieron simplemente la tasa de desaparición del etanol en sangre durante las dos horas posteriores después de terminar la administración. La observación de la policía parece ser correcta, ya que la tasa de descenso del nivel de alcohol en sangre y la tasa de metabolismo del alcohol eran notablemente superiores en los blancos que para cualquiera de los otros dos grupos nativos, que eran casi idénticos en las tasas de metabolismo y eliminación. Fenna et al. también presentaron evidencia de que estas diferencias en la tasa metabóli- 
ca no se deben a diferencias en la dieta o, aunque existe cierta adaptación, a experiencia diferencial con el alcohol.

No hay un estudio similar con grupos orientales, pero Ewing et al., (1974) informaron de que tras la ingestión de etanol, los niveles globales de acetaldeido de los sujetos orientales excedían a aquellos de los sujetos occidentales una indicación más de que los dos grupos difieren bioquímicamente en su reacción al alcohol.

Así, parece que tenemos pueblos relacionados racialmente, los grupos de chinos y de indios y esquimales americanos, ambos similares entre sí en sus reacciones fisiológicas y metabólicas al alcohol, ambos marcadamente diferentes del grupo caucasiano. Sin embargo los dos grupos mongoloides son polos opuestos en los efectos comportamentales del alcohol. Para los chinos, el alcohol parece ser un mucho menos problema social de lo que lo es para la mayoría de los grupos caucasianos americanos, mientras que para los indios y los esquimales, es considerablemente más un problema social (2). Por qué esto es así, es por supuesto, un rompecabezas absorbente, cuyá solución parece requerir una vez más, los insights y los conceptos de ciencias sociales. Mi propia explicación informal es que por haber sido ilegal que los indios bebieran o tuvieran licor durante tantos años, pueden haber desarrollado un patrón de bebida claramente único. Cuando obtenían licor (lo que, según se dice, no parece haber sido un gran problema), pueden muy bien habérselo bebido tan pronto como fuera posible para evitar la interferencia de algún oficial de la ley o misionero excesivamente celoso de su deber. Si esto es así, se bebieron su licor antes de que les pudiera poner enfermos.

Cualquiera que sea la solución de este rompecabezas en concreto, los biólogos continuarán casi con seguridad construyendo sobre y quizá reemplazando el trabajo de los científicos sociales en este área. Mi sospecha es que la determinación de las condiciones que han llevado a un grupo mongoloide a la sobriedad y al otro grupo al exceso puede muy bien llevar a una mayor comprensión de la etiología de la adicción al alcohol.

\section{Explicaciones farmacológicas de consumo de cigarrillos}

Como ejemplo final de un enfoque biológico versus psicolǵico de un fenómeno comportamental, describiré mi propio trabajo sobre el consumo de cigarrillos un comportamiento sobre él casi todo el mundo estará de acuerdo en que incluye tanto componentes psicológicos como biológicos. Por una parte, el fumador es un yonqui. Está colgado, adiccionado y lo que sea que estas palabras signifique psicológicamente, está tocado. En algún lugar hay una serie de células que, cuando se agotan empiezan a enviar señales para fumar.

Por otra parte casi cualquier fumador puede convencerte a tí y a sí mismo de que hay principalmente componentes psicológicos en el acto de fumar. Te convencerán de que fumar les relaja; de que fuman más cuando están nerviosos; de que fumar les ayuda a trabajar; etc. En resumen, fumar sirve a alguna función psicológica; hace algo positivo para el fumador, y esta es la razón por la que fuma. Este énfasis en las propiedades funcionales de fumar está en el meollo de prácticamente cada intento psicológico serio para la comprensión del consumo de tabaco. Presumiblemente, la nicotina, el alquitrán o algún componente al fumar es tan gratificante que, a pesar de los bien

(2)Stewart (1964) informa de que en los Estados Unidos, el alcohol está relacionado con los arrestos de indios trece veces más frecuentemente de lo que lo está con los arrestos de chinos y japoneses. Los indios tienen la tasa más alta de crimenes relacionados con el alcohol y los chinos y japoneses la más baja de entre todos los grupos identificados racialmente. 
propagados peligros, el fumador no está dispuesto o no puede dejar la costumbre. Sin duda el último elogio del acto es la sugerencia de Marcovitz de que

como fenómeno psicológico, fumar es comparable al rito de la Eucaristía. Allí el comunicante incorpora pan y vino y haciéndolo así introduce simbólicamente al Señor Jesucristo. Este es un proceso consciente, con la esperanza de la identificación de obtener algunos de los atributos de Jesús. Igualmente, el fumador incorpora el humo, introduciéndose en una fantasía inconsciente de algún objeto que le conferirá sus poderes mágicos. (p. 1082)

Entre estos poderes mágicos, fumar sirve para "delimitar la imagen corporal en la búsqueda del sentido de sí mismo", para "aliviar el miedo inconsciente de ahogo"; y para servir como "prueba de inmortalidad" (p. 1082, 1083). Aunque nadie ha igualado el panegírico de Marcovitz, casi todos los intentos de explicar el hábito han supuesto que hace algo positivo al fumador. Y esta es una suposición que comparte el mismo fumador, ya que los cuestionarios (e.g., Coan, 1973; Tomkins, 1968) indican que los fumadores empedernidos informan que los cigarrillos les relajan o les estimulan, les tranquilizan, les da algo que hacer con las manos, etc. En resumen, tanto para el psicólogo como para el fumador, el acto de fumar es funcional; hace algo por el fumador, y esta es la razón por la que fuma. En mi estudio, me he centrado en una de las supuestas motivaciones de fumar. Los fumadores informan en gran medida que fuman más cuando están tensos, nerviosos, o hartos, y también informan de que fumar les tranquiliza. Fumar, así, sirve a una respetable función psicológica y esta es supuestamente una de las motivaciones para y explicaciones de fumar frente al estrés.

Antes de preocuparnos sobre las interpretaciones de estos hechos, asegurémonos de que son hechos. Primero, ¿aumenta el consumo de tabaco con el estrés? La información disponible indica que sí. En dos experimentos casi idénticos, Schachter, Silverstein y Perlick (1977) manipularon el estrés dentro del contexto de experimentos supuestamente destinados para medir la sensibilidad táctil. En condiciones de mucho estrés se midió tal sensibilidad mediante la administración esporádica, en una prueba experimental, de una serie de descargas intensas y dolorosas. En las condiciones de poco estrés, las descargas eran un hormigueo apenas perceptible. Entre los intervalos de prueba, los sujetos, todos fumadores, eran libres de fumar o no fumar, según les pareciera. En ambos estudios los sujetos fumaron mucho más en las condiciones de mucho estrés que en las de poco estrés.

Volviendo a los efectos de fumar sobre el estrés, a continuación preguntamos si fumar reduce el estrés. La respuesta parece ser que depende de como lo mires. Silverstein (1976), en una modificación de un experimento diseñado por Nesbitt (1973), intentó, en el contexto de un estudio sobre percepción táctil, contestar a la pregunta midiendo cuánta descarga eléctrica estaba el sujeto dispuesto a soportar. El procedimiento exigía que los electrodos estuvieran colocados en los dedos del sujeto, que este estaría dispuesto a una serie de descargas de voltaje cada vez mayor, y que informaría cuando pudiera sentir la primera descarga después cuando la descarga empezara a ser dolorosa y finalmente cuando la descarga fuera tan dolorosa que no pudiera soportarla más. Silverstein supuso que cuanto más nervioso y tenso estuviera el sujeto, menos dolor estaría dispuesto a soportar. Hubo cuatro grupos experimentales fumadores que fumaron cigarrillos de alto contenido en nicotina durante el experimento, los que fumaron cigarrillos de bajo contenido en nicotina durante el experimento, los que no fumaron nada en todo el tiempo y un grupo de no fumadores que fumaron.

Los resultados de este experimento se muestran en la figura 1. Las ordenadas recogen el número de descargas que los sujetos soportaron antes de rendirse. Está claro que los fumadores soportan más descargas cuando fuman cigarrillos de alto contenido 
en nicotina que cuando los fuman con bajo contenido en nicotina, y que soportan el mínimo número de descargas cuando no fuman. Dado este patrón, se ofrecen varias interpretaciones: o la nicotina disminuye la ansiedad, o la falta de nicotina aumenta la ansiedad. La elección depende, por supuesto, de la posición del grupo de no fumadores quienes, tal como se puede ver en la figura, soportaron prácticamente el mismo número de descargas que los fumadores de alto contenido en nicotina. Parecería, así, que el consumo de tabaco no es reductor de la ansiedad, sino que más bien, que no fumar o la insuficiencia de nicotina es, para el fumador empedernido, un incrementador de la ansiedad.

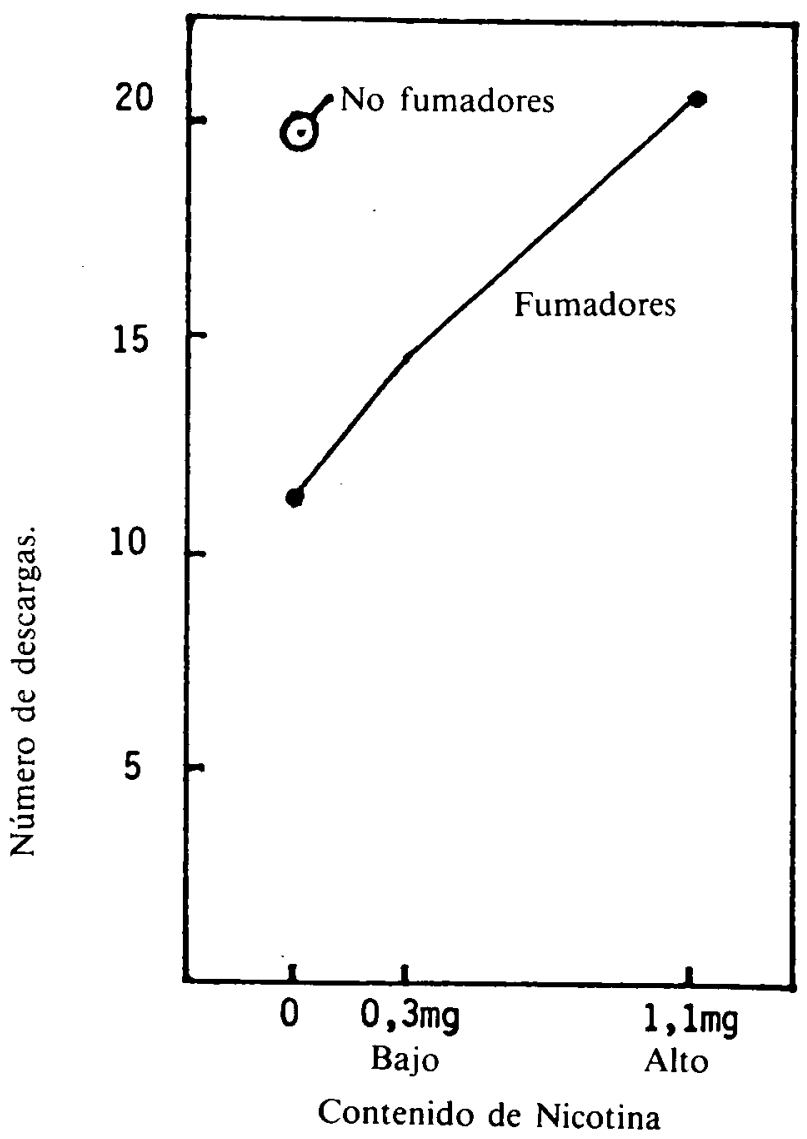

Fig. 1. Efectos de la nicotina en la tolerancia a la descarga.

Precisamente apareció el mismo patrón de resultados de un estudio experimental de la irritabilidad dirigido por Perlick (1977). En el contexto de un estudio sobre ruidos provocados por la aviación, los sujetos que veian un programa de televisión clasificaron cómo de altos (volúmen) y molestos encontraban una serie de vuelos simulados. Durante la sesión experimental, a los sujetos que eran fumadores empedernidos se les permitió fumar a voluntad cigarrillos con alto contenido en nicotina, en una de las condiciones, cigarrillo con bajo contenido de nicotina en otra condición, y se les 
prohibió fumar en la tercera condición experimental. Por último había un grupo de no fumadores. Los resultados se presentan en la Figura 2, donde se ve que los fumadores que fumaban cigarrillos de alto contenido en nicotina estaban notablemente menos irritados por esta serie de ruidos odiosos que los fumadores a los que se restringió a cigarrillos de bajo contenido en nicotina o que a los que se les prohibió fumar. Sin embargo, estos fumadores de alto contenido en nicotina no estaban ni menos ni más irritados que el grupo de no fumadores. De nuevo parece que fumar no hace al fumador menos irritable o vulnerable al enfado; es no fumar, o la insuficiencia de nicotina, lo que le hace más irritable.

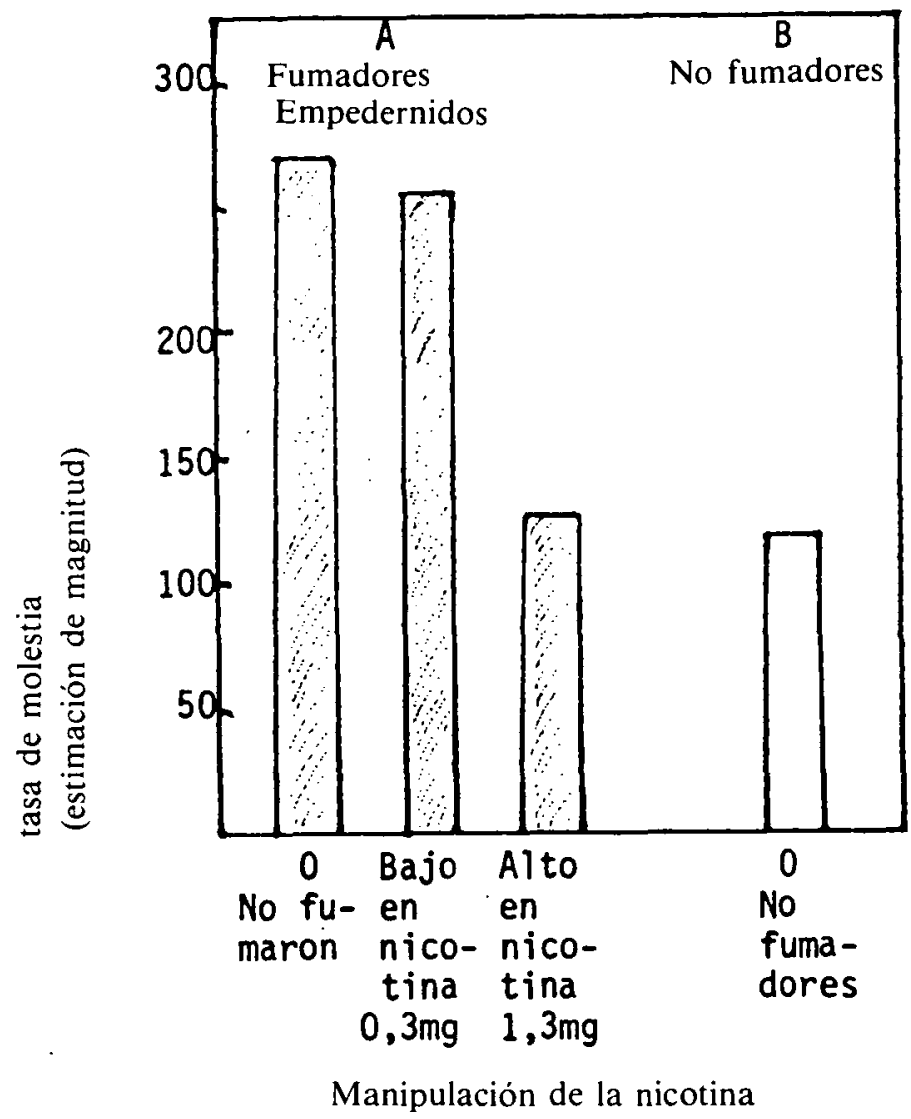

Figura 2. Los efectos de la nicotina sobre la irritabilidad.

Este mismo patrón parece ser característico del comportamiento psicomotor, así como del emocional. Heimstra, Bancroft and DeKock (1967) examinaron la hipótesis de que fumar facilita la ejecución al conducir, comparando fumadores irregulares con libertad para fumar a voluntad, fumadores deprivados, y no fumadores en una prueba simulada de conducción de 6 horas. En medidas variadas de seguimiento y vigilancia, los fumadores irregulares no lo hicieron ni mejor ni peor que los no fumadores, pero lo hicieron notablemente mejor que los fumadores deprivados. 
Una y otra vez, nos encontramos el mismo patrón: fumar no mejora el humor ni tranquiliza el fumador ni mejora el rendimiento cuando se le compara con el no fumador. Sin embargo, no fumar, o nicotina insuficiente, le hace mucho peor en todas las dimensiones (3).

Dado este hecho persistente, ¿cómo, entonces, explicar el hecho de que el fumador fuma más cuando está estresado?. Se puede, obviamente, explicar los efectos generales debilitadores de la poca o ninguna nicotina, con la suposición de que el fumador deprivado está en fase de absentención, pero sólo esta suposición no puede explicar los efectos del estrés en la tasa de consumo de tabaco, a no ser que se suponga que el estrés disminuye de alguna manera la reserva disponible de nicotina. Y esta hipótesis, claro, puede explicar este patrón de datos sólo si el fumador, un adicto, está fumando para mantener la nicotina a un nivel constante.

\section{Nicotina como Adicción}

En la suposición de que una manifestación de la adicción es la regularidad en la toma de nicotina, los estudios sobre el asunto o han cargado por anticipado a los sujetos con distintas cantidades de nicotina, o han manipulado el contenido de nicotina de los cigarrillos disponibles. Aunque los resultados de muchos estudios en este área no son completamente consistentes (ver Schachter, 197.7, para una revisión de la literatura), la mayoría de los estudios indican que los fumadores regularán la nicotina, en especial sin son fumadores empedernidos desde hace mucho tiempo. Una descripción de un estudio de esos sujetos hará entender la magnitud del efecto. Schachter (1977) consiguió la cooperación de un grupo de sujetos, todos los cuales habian fumado una cajetilla o más al día por lo menos durante 19 años. Para hacer el experimento, estos sujetos acordaron fumar sólo los cigarrillos del experimentador, y en semanas alternas, a cada sujeto se le regalaron cartones de cigarrillos especialmente preparados y empaquetados que contenían $1,3 \mathrm{mg}$. de nicotina por cigarrillo, ó $0,3 \mathrm{mg}$. de nicotina por cigarrillo. Por la noche los sujetos apuntaban el número de cigarrillos que habían fumado.

Los efectos de la manipulación de la nicotina se muestran en la Tabla 2. Obviamente, la manipulación tenía un efecto consistente sobre estos antiguos fumadores empedernidos; cada uno de ellos fumó más cigarrillos de bajo contenido en nicotina que de alto contenido. Como promedio, hubo un $25 \%$ de incremento $(p<, 01)$ en el consumo de tabaco acompañado a la manipulación del contenido en nicotina.

(3) Hay, por supuesto, una interpretación alternativa a este patrón consistente. Más que indicar insuficiencia, es posible que las personas que se hacen fumadoras están por naturaleza más asustadas de la descarga, más irritadas por el ruido, y son peores conductoras que las personas que nunca se hacen fumadoras, y que para tales personas fumar es, desde luego, tranquilizador y mejora su rendimiento psicomotor. Aunque nada más que un estudio longitudinal podria inequivocamente asentar el asunto, hay que tener en cuenta que ha habido un enorme número de estudios que compararon a fumadores y no fumadores en casi cada dimensión de personalidad imaginable. Smith (1970), en su revisión de esta extensa literatura, concluye que las únicas variables que con consistencia razonable discriminan entre fumadores y no fumadores son extroversión y tendencias antisociales. $E$ incluso en estas variables, las diferencias son todas muy pequeñas. Para este escritor, parece particularmente raro que la selección, más que la insuficiencia, puedan explicar las numerosas consecuencias dolorosas de no fumar o de la nicotina inadecuada, ya que aceptar esta interpretación exige que conceda que él era enteramente un ser humano viciado e infeliz antes de empezar a fumar, y que lo sería de nuevo si fuera a dejar este hábito. 
Tabla 2: Efectos del contenido de nicotina sobre el consumo de tabaco.

Características de los sujetos

Consumo de cigarrillos (por dia)

\begin{tabular}{cccccccc} 
Sujeto & Edad & Sexo & $\begin{array}{c}\text { Años } \\
\text { como } \\
\text { fumador } \\
\text { serio }\end{array}$ & $\begin{array}{c}\text { No de cig. } \\
\text { por día (auto } \\
\text { informe }\end{array}$ & $\begin{array}{c}\text { Baja } \\
\text { nicotina } \\
\text { (.3 mg.) }\end{array}$ & $\begin{array}{c}\text { Mucha } \\
\text { nicotina } \\
\text { (1.3 mg.) }\end{array}$ & $\begin{array}{c}\text { Aumento } \\
\text { \% } \\
\text { (mucha } \\
\text { a poca) }\end{array}$ \\
\hline & & & & & & & \\
J.A. & 52 & H & 30 & 30 & 31.25 & 21.50 & +45.3 \\
S.S. & 37 & H & 22 & 40 & 55.00 & 40.50 & +35.8 \\
R.R. & 38 & H & 19 & 40 & 42.50 & 30.75 & +38.2 \\
R.S. & 43 & H & 27 & 20 & 22.75 & 20.00 & +13.8 \\
D.R. & 47 & H & 29 & $40-45$ & 70.75 & 58.75 & +20.4 \\
R.A. & 50 & V & 40 & 30 & 30.25 & 26.25 & +15.2 \\
J.E. & 52 & V & 33 & 33 & 48.00 & 44.25 & +8.5 \\
Media & 45.6 & & 28.6 & 33.6 & 42.93 & 34.57 & +25.3 \\
\hline
\end{tabular}

Parece asi, que los antiguos fumadores empedernidos regulan la nicotina. Dado que la manipulación supuso una diferencia cuádruple en el contenido de nicotina, mientras que el consumo de tabaco aumentó sólo un $25 \%$, parece ser, como mucho, una regulación tosca e imprecisa. Hay sin embargo, razones para creer que la regulación de la nicotina es considerablemente más precisa de lo que estos datos sugieren. Primero, varios estudios (Ashton y Watson, 1970; Herman, 1974; Schachter, Silverstein y Perlick, 1977) informan de que los fumadores dan más caladas a los cigarrillos bajos en nicotina que a los altos - un claro mecanismo para aumentar la toma de nicotina. Segundo, dada la escala de contenido de nicotina de este estudio, una regulación precisa era prácticamente imposible. Por ejemplo, un sujeto que normalmente fumara 2 cajetillas diarias de cigarrillos con $1,3 \mathrm{mg}$. de nicotina tendría que fumar casi nueve paquetes diarios de nuestros cigarrillos bajos en nicotina para tomar su dosis de nicotina acostumbrada. Bajo estas circunstancias casi cualquier teoría de la adicción predeciría síndrome de abstención al sujeto de cigarrillos bajos en nicotina. Aunque desgraciadamente no se tomó ninguna medida en este estudio para medir la abstención, hay dramática evidencia anecdótica de que los sujetos que fueron peores reguladores en este estudio estaban en estado de notable emotividad irritada y explosiva mientras consumian los cigarrillos bajos en nicotina. Apoyando esta observación, Perlick (1977) y Silverstein (1976) han demostrado experimentalmente que los grandes fumadores que consumen cigarrillos bajos en nicotina están notablemente más nerviosos e irritables que cuando están consumiendo cigarrillos altos en nicotina.

Parece así que los fumadores empedernidos ajustan su tasa de consumo de tabaco como para mantener la nicotina a un aproximado nivel constante. Para explicar este hecho, se puede suponer que hay una especie de máquina interna que detecta el nivel de nicotina y acordemente regula el consumo de tabaco. Para entrar en la consideración de la naturaleza de tal regulación, revisaremos algunos de los hechos básicos sobre la destrucción metabólica y la excreción de la nicotina. Tal como resumieron Goodman y Gilman (1958):

La nicotina se absorbe rápidamente... por la mucosa oral y gastrointestinal y por el tracto respiratorio... la nicotina se altera quimicamente en el cuerpo, especialmente en el higado pero también en los riñones y pulmones. La frac- 
ción de nicotina que escapa a la desintoxicación se elimina completamente como tal en la orina junto con las formas químicamente alteradas. La tasa de excreción del alcaloide es rápida y aumenta linealmente con la dosis... cuando la orina es alcalina, sólo se excreta un cuarto de la nicotina que se excreta cuando la orina es ácida; esto se explica por el hecho de que la base nicotina se absorve en la orina alcalina. (p. 622).

El efecto de la acidez o $\mathrm{pH}$ de la orina sobre la tasa de excreción de la nicotina inalterada sugiere, dado que los fumadores parecen regular la nicotina, que el $\mathrm{pH}$ de la orina puede afectar la tasa de consumo de tabaco. Sin embargo, si hay que anticipar el efecto de alguna consecuencia, depende de la proporción de nicotina inalterada que se excreta. Se pueden hacer estimaciones razonablemente precisas del trabajo de Beckett y sus colegas. Beckett, Rowland y Triggs (1965) han mostrado que los sujetos que fuman 20 cigarrillos diarios excretan una media de $1,0 \mathrm{mg}$. de nicotina por minuto bajo condiciones normales, $5,0 \mathrm{mg}$. de nicotina por minuto cuando la orina se hace ácida mediante la administración oral de clorido de amonio, y $0,1 \mathrm{mg}$. después de la administración oral del alcaloide bicarbonato sódico. En otro estudio, Beckett y Triggs (1967) han demostrado que los fumadores cuya orina se ha mantenido ácida excretan en forma inalterada un $35 \%$ de las cantidades conocidas de nicotina que se han administrado bien por vía intravenosa, inhalación de vapor de nicotina o fumando. Uniendo estos datos, parece razonable estimar que la proporción de nicotina que será excretada en forma inalterada variará con la acidez manipulada de la orina, del siguiente modo: $\mathrm{Si}$ la orina es ácida se excretará el $35 \%$ de la nicotina; si es normal, el $7 \%$, y si es alcalina menos del $1 \%$.

Obviamente las proporciones exactas variarán con el $\mathrm{pH}$ preciso de la orina. Sin embargo, una cosa parece clara: Dada la bastante baja cantidad de nicotina inalterada excretada bajo condiciones normales o de placebo, aumentar la alcalinidad de la orina puede en el mejor de los casos tener efectos insignificantes sobre el nivel de nicotina en plasma, mientras que aumentar la acidez de la orina puede tener potencialmente efectos sustanciąles en el nivel de nicotina en plasma. Así, se asume, primero que los cambios en el pH de la orina se reflejan en la orina en circulación y segundo, que si las cantidades fumadas varían con los cambios en el nivel de nicotina en plasma, debería esperarse que incrementos experimentales de la acidez de la orina aumentarán las cantidades fumadas.

Para probar esta hipótesis, Schachter, Kozlowski, y Silverstein (1977) manipularon el pH de la orina en semanas alternas administrando a un grupo de trece fumadores dosis sustanciales diarias de un placebo o de los agentes acidificadores vitamina $C$ (ácido ascórbico) y acidulina (hidrocloruro de ácido glutámico). A los sujetos se les dieron cartones de sus cigarrillos favoritos y se les pidió que llevaran la cuenta de los que fumaban cada día del estudio. Los efectos de estas manipulaciones sobre el consumo de tabaco se presentan en la Tabla 3, donde se observa que la acidificación se acompaña de un aumento en el consumo de tabaco. Durante el período en el que tomaban uno de los agentes acidificadores, los sujetos fumaron un $20 \%$ más de cigarrillos que durante el tiempo que tomaron un placebo de almidón de maíz.

Debe observarse concretamente que de acuerdo con la magnitud de los efectos farmacológicos (Beckett, Rowland, y Triggs, 1965; Beckett y Triggs, 1967; Haagy Larson, 1942), este aumento del $20 \%$ no es un efecto particularmente grande. A juzgar por el trabajo de Beckett y sus colegas sobre la excreción de la orina, se esperaria como mucho, aproximadamente un aumento de un $30 \%$ en el consumo de tabaco incluso con una manipulación acidificante fuertemente efectiva, que la nuestra no era. Parece claro que, de los dos mecanismos principales que tiene el cuerpo para deshacerse de la nico- 
Tabla 3: Efectos de la vitamina $C$, acidulina y placebo sobre el consumo de tabaco.

Condición

Vitamina C

Placebo

Acidulina

Comparación

Vitamina $C$ versus placebo

Acidulina versus placebo
Cigarrillos fumados

al día

16,7

23,1

28,1

Significación
$\mathrm{p}<, 05$
$\mathrm{p}<, 01$
$\mathrm{p}<, 05$
$\mathrm{p}<, 01$

Porcentaje medio de cambio respecto al placebo

$+19,8$

$+20,9$

tina - destrucción enzimática y excreción urinaria de la nicotina inalterada- la excreción urinaria juega con mucho, el menor papel en el fumador empedernido. A pesar de todo, la acidificación afecta al comportamiento de fumar, y este hallazgo al menos aumenta la posibilidad de que pueda ser útil invocar a este trocito de maquinaria farmacológica para comprender algunos de los supuestos determinantes psicológicos y situacionales de la tasa de consumo de tabaco. Se puede concebir así, que los eventos que estimulan el consumo de tabaco, lo hagan mediante su acción en el pH de la orina.

Tabla 4: Efectos del estrés académico sobre el pH de la orina.

Sujeto Día de estrés Día de control Control de estrés

\section{A. Charla-Coloquio}

$\begin{array}{clll}\text { E.G. } & 5,50 & 6,35 & -, 85 \\ \text { H.T. } & 5,70 & 5,95 & -, 25 \\ \text { M.C. } & 6,70 & 6,90 & -, 20 \\ \text { H.K. } & 5,50 & 6,20 & -, 70 \\ \text { S.S. } & 5,40 & 6,45 & -1,05\end{array}$

B. Defensa oral del doctorado
E.D.
5,40
7,10
$-1,70$
A.L.
6,00
6,20
$-, 20$

C. Examen global de doctorado
B.S.
5,85
5,80
$+, 05$
I.S.
5,20
5,70
$-, 50$
D.P.
5,40
5,70
$-, 30$

Todos los sujetos

(media)

5,67

6,24

$-, 57$ 
Para saber si esta hipótesis tenía algún mérito como posible explicación de la relación estrés-fumar, Schachter, Silverstein, Kozlowski, Herman, y Liebling (1977) examinaron los efectos de una variedad de estresores académicos sobre el $\mathrm{pH}$. En uno de los estudios, los sujetos orinaron inmediatamente antes de un suceso obviamente estresante, tales como dar una conferencia coloquio o hacer unos exámenes de doctorado orales o globales. Y como control, estos mismos sujetos orinaron precisamente a la misma hora en días rutinarios no estresantes. Los resultados se presentan en la Tabla 4, donde se observa que para nueve de diez sujetos la orina es considerablemente más ácida en días de estrés que de control.

Precisamente se manifiesta el mismo patrón en otro estudio de los efectos del estrés (Schachter, Silverstein y Perlick, 1977). A nueve de los 20 miembros de un seminario para estudiantes no licenciados se les exigió leer material muy técnico y preparar informes orales de 10 a 15 minutos de duración para la clase. Del resto de los estudiantes sólo se esperaba que escucharan los informes. Todos los estudiantes orinaron un poco antes de la clase. Para los informadores la media del pH era de 6,01 y para los oyentes era de $6,67(\mathrm{p}<0,05)$. Antes de una clase de control, el $\mathrm{pH}$ era idéntico para los dos grupos de estudiantes. Parece que el estrés, por lo menos del tipo propio de la vida académica, acidifica la orina, hallazgo que por lo menos anima a la explicación de una interpretación farmacológica de la conducta de fumar.

Revisión de la línea argumental hasta el momento: Se ha informado muchas veces de que el consumo de tabaco aumenta con el estrés y de que fumar tranquiliza observación que parece concordar con y apoyar la afirmación de que la nicotina o el alquitrán o algún componente del acto de fumar es reductor de la ansiedad. Los hechos experimentales están peculiarmente en desacuerdo con esta interpretación. El consummo de tabaco aumenta desde luego con el estrés, pero los fumadores que fuman ni están más ni menos tranquilos que un grupo de no fumadores. Sin embargo, están mucho más tranquilos que los grupos de fumadores a los que o bien se les ha prohibido fumar o bien sólo fuman cigarrillos bajos en nicotina. Este hecho se puede interpretar no como indicador de que fumar reduce la ansiedad sino como muestra de que no fumar o nicotina insuficiente aumenta la ansiedad. En efecto, el fumador fuma más durante el estrés a causa de la aparición de síntomas de abstención y no a causa de ninguna propiedad psicológica de la nicotina o del acto de fumar. Tal información es plausible si se supone que el fumador fuma para mantener la nicotina a un nivel constante y que hay algo en el estado del estrés que disminuye el suministro de nicotina al cuerpo. Se ha descrito una serie de estudios que, a través de los efectos del pH urinario en la tasa de excreción de la nicotina, sugieren unos mecanismos bioquímicos que podrían explicar estos hechos.

Aunque esta elegante yuxtaposición de hechos hace casi irresistible la conclusión de que la mente del fumador está en la vejiga, obviamente apenas estamos en posición de desechar explicaciones psicológicas de la conducta de fumar. Aunque "la reducción de la ansiedad" parece, por ahora, una explicación particularmente insatisfactoria de la relación estrés-fumar, todavía son factibles innumerables explicaciones puramente psicológicas. Ferster (1970), por ejemplo, ha intentado explicar la relación en estos términos:

Con el aumento de los síntomas emocionales hay frecuentemente un cese de la mayoría del repertorio en curso en el que la persona pueda ocuparse. Con tal decremento temporal en la frecuencia de la mayoria de los items del repertorio de una persona, la importancia relativa de incluso los reforzadores menores, aumenta enormemente. Así, la posición relativa de consumo de tabaco en el repertorio completo aumenta considerablemente cuando otros items más 
importantes del repertorio están disminuidos. Fumar se convierte en algo que hacer cuando ningún otro comportamiento es aporpiado.

En resumen, aunque el efecto del pH sobre la eliminación de la nicotina es un hecho farmacológico bien establecido, puede tener poco, si es que tiene algo, que ver con los efetos del estrés sobre el consumo de tabaco, ya que es ciertamente plausible que el estrés, con o sin cambios en el pH que lo acompañen, afectará a la tasa de consumo de tabaco. Para saber si los cambios en el $\mathrm{pH}$ son una explicación necesaria y suficiente de la relación estrés-fumar, parece claro que debemos enfrentar experimentalemente a la mente contra la vejiga. Esto intentaron hacer Schachter, Silverstein y Perlick (1977) en un experimento que manipulaba independientemente el estrés y el $\mathrm{pH}$ de la orina. Si es verdad que los cambios en el $\mathrm{pH}$ son una parte necesaria de la maquinaria, deberíamos esperar más consumo de tabaco en condiciones de mucho que de poco estrés cuando el $\mathrm{pH}$ no esté controlado, y ninguna diferencia entre las dos condiciones cuando el $\mathrm{pH}$ esté estabilizado experimentalmente. $\mathrm{Si}$, por otra parte, los cambios del $\mathrm{pH}$ son irrelevantes para la relación estrés-fumar, debería haber más consumo de tabaco en condiciones de mucho que de poco estrés sin importar el estado de la orina.

En este estudio el estrés también estaba manipulado por descargas eléctricas. De hecho, se replicó el experimento ya descrito sobre la relación del estrés con el consumo de tabaco (Schachter, Silverstein et al., 1977) con una modificación importante. En un par de condiciones la manipulación de mucho o poco estrés empezó 50 minutos después de que los sujetos tomaran un placebo; en las otras condiciones, 50 minutos después de que los sujetos hubieran tomado 3 gramos de bicarbonato sódico - un agente que casi garantizaba elevar rápidamente el $\mathrm{pH}$ urinario y estabilizarlo durante un rato a niveles altamente alcalinos. Comprobando primero la efectividad de las manipulaciones, observé que en las dos condiciones placebo, el $\mathrm{pH}$ disminuía en la condición de mucho estrés y permanecía igual en la condición de poco estrés. En las dos condi-, ciones de bicarbonato, muy al contrario, el $\mathrm{pH}$ aumentó notablemente desde el principio al fin del experimento, y la manipulación del estrés no tuvo absolutamente ningún efecto sobre el $\mathrm{pH}$.

A continuación observé que, en una serie de medidas de autoinforme, la manipulación del estrés tuvo mucho éxito tanto en la condición de placebo como en la der bicarbonato. Así, obviamente, se habían establecido las condiciones necesarias para enfrentar las explicaciones psicológica contra farmacológica de los efectos del estrés sobre el consumo de tabaco. Los sujetos en condiciones de mucho estrés están mucho más tensas que los sujetos en condiciones de poco estrés, tanto si han tomado un placebo como si han tomado bicarbonato. Sin embargo, en las condiciones de placebo en las que el $\mathrm{pH}$ no se controla, el estrés acidifica, mientras que en las condiciones de bicarbonato, no lo hace.

Los efectos de estas manipulaciones sobre el consumo de tabaco se presentan en la Figura 3, que muestra el número medio de caladas que tomaron los sujetos en cada condición, una vez que habia empezado la manipulación del estrés. Está claro que con el placebo hay considerablemente más consumo de tabaco en condiciones de mucho estrés que de poco estrés, mientras que con el bicarbonato, el estrés no tenía efecto sobre el consumo de tabaco (interacción $\mathrm{p}\langle, 01$ ). Parece por tanto que el consumo de tabajo bajo el estrés tiene poco que ver con las necesidades psicológicas, sensoriales o manipulativas que presumiblemente se activan con el estado de estrés, pero se explica por los efectos del estrés en la tasa de excreción de la nicotina. El fumador bajo estrés fuma para reaprovisionar el suministro de nicotina, no para disminuir la ansiedad.

Dados los hechos de la Figura 3, nos enfrentamos con una formidable pregunta que, reducida a lo esencial, es esta: ¿Entonces dónde está la psicologia? ¿Qué es de 
Figura 3. Efectos del bicarbonato sódico y del placebo sobre el consumo de tabaco bajo estrés.

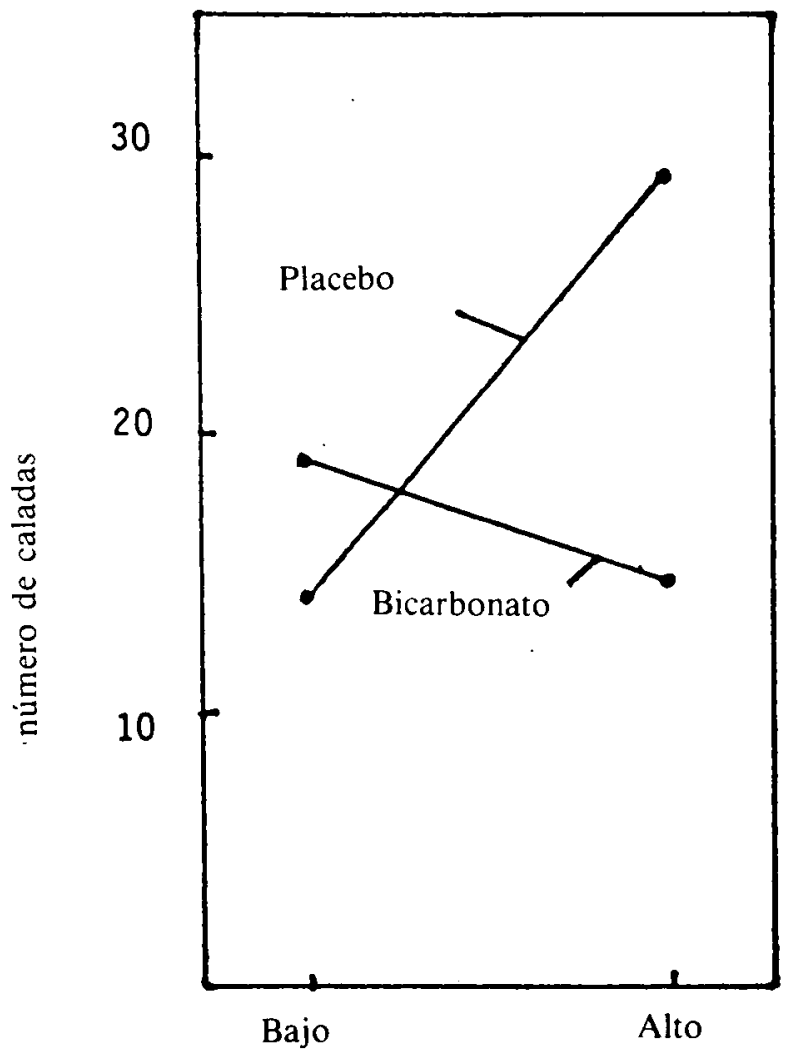

Grado de estrés

las necesidades de la dependencia oral o la fuerza del hábito, o la atribución inadecuada, si, como parece ser el caso del estrés, todo depende en la concentración del ión hidrógeno en la orina? Obviamente este ha sido un intento abiertamente reduccionista de explicar algunos de los efectos de las variables psicológicas sin utilizar el equipamiento conceptual de la psicología. Yo creo que en caso del estrés el intento ha tenido éxito, ya que, dados los hechos descritos, los intentos de formular la relación estrésfumar en términos de necesidades de dependencia oral (Mercovitz, 1969) o de la teoría de la atribución (Nesbitt, 1973; Schachter, 1973) o de la teoría del aprendizaje (Ferster, 1970; Hunt, 1970) parecen constructos innecesarios y hechos ad hoc. El consumo de tabaco aumenta bajo estrés porque esa es la forma en que está hecha la maquinaria biológica, y tiene tanto sentido preguntar psicodinámica, cognitiva o situacionalmente porque aumenta el consumo de tabaco bajo estrés como lo tendria preguntar por qué psicológicamente va más deprisa el coche cuando piso el acelerador.

\section{Resumen}

He presentado con algún detalle tres casos que han comparado los enfoques de las ciencias biológica y sociológica, a un comportamiento o patrón de comportamiento 
concreto. Estos comportamientos difieren obviamente en la especificidad y certeza con que se puede identificar la causación biológica, pero comparten una historia común. Todos son casos de la tendencia persistente en las ciencias sociales para interpretar psicológica y funcionalmente, comportamientos y enfermedades que pueden ser más eficazmente comprendidas en términos puramente biológicos o incluso mecánicos. Esta tendencia es, por ahora una vieja historia en psicología médica. Es una historia que, sospecho se repetirá en la psicología social o de la personalidad. Incluso ahora, no parece demasiado inverosímil sugerir que mucho de lo que consideramos relaciones interpersonales - los odios, pasiones, amores, agresiones y ansiedades- pueden con el tiempo entenderse mejor en términos bioquímicos que psicológicos. ¿Quién no se ha observado con sorpresa mientras él mismo explotaba de enfado o de euforia sin sospechar que había algo más "glandular" que situacionalmente inducido en estas reacciones?. Y, desde luego, hay rarezas médicas como el síndrome de Lesch-Nyhan un desorden en que la extrema hostilidad interpersonal así como la automutilación están aparentemente causadas por la ausencia de una única enzima, la hipoxanthina-cuanina fosforibosil transferasa. Hasta ahora nadie pretende tener el más ligero atisbo en la relación entre la ausencia de transferasa y este extraño comportamiento, pero parece no haber dudas de que están asociados. Debo hacer notar que este es el mismo nivel de ignorancia con el que nos encaramos en nuestra comprensión del síndrome Tourette. Por qué un exceso de dopamina nos llevaría a maldecir compulsivamente o a un tic como eco, es un completo misterio.

A pesar de nuestra habilidad para implicar a una sustancia bioquímica como culpable, el hecho de que apenas hayamos arañado la comprensión de estas enfermedades, pone en claro que estamos muy lejos de la utopía enciclopédica exigida por el enfoque reduccionista del comportamiento, antes de que éste llegue a ser bastante más que una declaración de fé científica. Sin embargo, incluso en estas etapas tempranas de comprensión, la simple asignación de un fenómeno a una causación biológica o psicológica de sí misma puede tener consecuencias profundas. En el caso del síndrome Tourette, es evidente que la atribución a una causa psicológica llevó a décadas de psicoterapia dolorosamente inefectiva. En cuanto al consumo de tabaco, puede muy bien ser que la atribución a una causa psicológica sea responsable del aumento de los peligros del hábito para la salud. El quid de la campaña antitabaco es simplemente "Abandona, y si no puedes o no quieres, cambia a un cigarrillo bajo en nicotina y alquitrán". Con el respaldo de la Sociedad Americana del Cáncer, el Colegio Real de Médicos y el Servicio de Salud Pública, este mensaje impregna los medios de comunicación de masas y parece ser responsable de la tediosa competición entre las compañías de tabaco por conseguir el cigarrillo más seguro, de la búsqueda de un aceptable cigarrillo libre de tabaco estimulada por el gobierno británico, y de las políticas de impuestos tales como las de la ciudad de Nueva York, que durante un tiempo gravó los cigarrillos por el contenido de nicotina y alquitrán en un esfuerzo aparente para utilizar la fuerza económica para ayudar al fumador a ayudarse a sí mismo. Es una suposición razonable el que, en buena parte, la campaña de poca nicotina y alquitrán se base en la idea de que el consumo de cigarrillos resiste desde una variedad de necesidades psicológicas, sensoriales y manipulativas, que probablemente también pueden ser tan bien satisfechas con un cigarrillo bajo en nicotina como con uno alto en nicotina.

Sin embargo, tal como hemos visto, hay evidencia de que la nicotina es adictiva y de que el fumador, un adicto, probablemente fuma para mantener la nicotina o uno de sus metabolitos activos a algún nivel óptimo. Si, asi, el fumador empedernido se cambia a marcas bajas en nicotina, puede muy bien terminar fumando más cigarrillos y dando más caladas a cada uno. Probablemente conseguirá, en el proceso de regula- 
ción de la nicotina, las mismas cantidades de nicotina y alquitrán, y dependiendo de la forma en que esté hecho el cigarrillo, probablemente inhalará más gases tales como monóxido de carbono, que parece ser por lo menos tan nocivo médicamente como la nicotina o el alquitrán en cuanto que está implicado en el aumento de riesgo de arterioesclerosis, isquemia cardiaca, daños al feto, etc. (Informe del "Surgeon General", 1972; Larson, Haag y Silvette, 1961). Si este cambio en el nivel de consumo de tabaco es permanente, el efecto neto del cambio a cigarrillos bajos en nicotina podría muy bien aumentar los peligros del consumo de tabaco. Desde este punto de vista, el fumador preocupado debería fumar cigarrillos altos, no bajos en nicotina.

Es evidente entonces, que la atribución de un fenómeno a una causa biológica o psicológica es más que un interés académico. Tiene consecuencias prácticas así como teóricas.

Una última palabra. Como supongo que es obvio que me siento atraído por las posibilidades del reduccionismo biológico, debo enfatizar que soy consciente de la importancia de los factores psicológicos y situacionales; de hecho mucho de mi trabajo (Schachter, 1971) ha tratado de la especificación de la interacción de los determinantes cognitivos, sociales y fisiológicos de los comportamientos emocionales y apetitivos de distintos tipos. Confieso, sin embargo, que los resultados de mi investigación sobre el consumo de tabaco me han dejado con una fascinación constante con las posibilidades, incluso ahora, de un enfoque grandemente reduccionista a los fenómenos sociales y comportamentales. Hay algo perversamente satisfactorio en la reducción de un comportamiento presumiblemente complejo al $\mathrm{pH}$ de la orina. Aparte de este valor gracioso sospecho, sin embargo, que el enfoque reduccionista tiene el potencial, incluso ahora, de proporcionar unos grandes insights de los problemas y áreas que han parecido ser campo exclusivo de los científicos sociales y humanistas - particularmente, anticipo, en una dirección bastante sorprendente: la comprensión de los aberrantes fenómenos de masas. Como este es el área en que para mí, los esfuerzos de la ciencia social han sido casi totalmente insatisfactorios ( ha habido todavía un análisis psicológico sociológico o histórico de la Alemania Nazi que hiciera este período de demencia humana comprensible?), tengo un optimismo prudente sobre la posibilidades de un enfoque biológico a algunos fenómenos de masas. Mi optimismo se basa en la perogrullada de que todos respiramos el mismo aire, bebemos el mismo agua, tomamos comida similar, fumamos cigarrillos similares, etc. Si algo biológico cambia o va mal, puede afectar a toda o a la mayoria de una población. Cuando se añade flúor a agua de una comunidad, quieran o no, todos aumentan el consumo de flúor, y cualesquiera que sean los efectos de esta sustancia, serán prácticamente universales dentro de esa comunidad. Cuando una gran porción de una población adicta trata de dejar de fumar o cambia a marcas bajas en nicotina, un número muy grande de personas de esa población estarán en abstinencia. Dado lo que sabemos de la abstinencia, esto significa grandes números de personas en un estado simultáneo de irritabilidad, irascibilidad, mal humor, etc. Se podría, con razón, anticipar en tal población, altas tasas de divorcios, asaltos y caos general. Este tipo de especulación se relaciona lo suficiente con tales frágiles esfuerzos especulativos, como el impacto de la ionización atmosférica sobre el humor o de la intoxicación atmosférica sobre el humor o de la intoxicación de plomo sobre la caida de Roma como para dejarle a uno algo intranquilo, pero quizá el lector estará de acuerdo en que hasta ahora la sobriedad ha sido la virtud principal de los enfoques más ortodoxos a los fenómenos de masas. 


\section{REFERENCIAS}

Abraham, K. Contributions to a discussion on tic. In K. Abraham (Ed.), Selected papers of Karl Abraham, M.D., translated by B.D. Strachey. London: London Hogarth Press, 1927.

Ashton, H. \& Watson, D.W. Puffing frequency and nicotine intake in cigarette smokers. British Medical Journal, 1970, 3, 679-681.

Barnett, M.L. Alcoholism in the Cantonese of New York City: An anthropologial study. In Oskar Diethelm (Ed.), Etiology of chronic alcoholims. Springfield: Charles C. Thomas 1955.

Beckett, A.H., Rowland, M., \& Triggs, E.G. Significance of smoking in investigations of urinary excretion rates of amines in man. Nature, 1965, 207, 200-201.

Beckett, A.H. \& Triggs, E.G. Enzyme induction in man caused by smoking. Nature, 1967, 216, 587.

Benedek, L. Zwangsmässiges schreien in anfällen als postencephalitische hyperkinese. Z. Ges. Neurol. Psychiatr. 1925, 98, 17-26.

Coan, R.W. Personalit, variables associated with swcking Journal of Personalit, and Social Psychology, 1973, 26, 86-104.

Drill, V. (Ed.). Pharmacology in medicine. New York: McGraw-Hill, 1958.

Ewing, J., Rouse, B., \& Pellizari, E.D. Alcohol sensitivity and ethnic background. American Journal of Psyhiatry, 1974, 131, 206-210.

Fenna, D., Mix, L., Schaefer, O., \& Gilbert, J.A.L. Ethanol metabolism in various racial groups. Canadian Medical Association Journal, 1971, 105, 472-475.

Ferenczi, S. Psycho-analytical observations on tic. International Journal of Psychoanalysis, 1921, 2, I-30.

Ferster, C.B. Comments on paper by Hunt and Matarazzo. In W.A. Hunt (Ed.), Learning mechanisms in smoking. Chicago: Aldine, 1970.

Goodman, L.S. \& Gilman, A. The pharmacological basis of therapeutics. New York: Macmillan, 1958.

Greenberg, L.A. Alcohol in the body. Scientific American, 1953, 189, 86-90.

Haag, H.B., \& Larson, P.S. Studies on the fate of nicotine in the body. I: The effect of $\mathrm{pH}$ on the urinary excretion of nicotine by tobacco smokers. Journal of Pharmacology and Experimental Therapeutics, 1942, 76, 235-239.

Heimstra, N.W., Bancroft, N.R., \& DeKock, A.R. Effects of smoking upon sustained performance in a simulated driving task. Annals of the New York Academy of Sciences, 1967, 142, 295-307.

Herman, C.P. External and internal cues as determinants of the smoking behavior of light and heavy smokers. Journal of Personlity and Social Psychology, 1974, 30, 664-672.

Hunt W.A. (Ed.). Learning mechanisms in smoking. Chicago: Aldine, 1970.

La Barre, W. Some observations on character structure in the Orient, II. The Chinese,

Pt. 2. Psychiatry, 1946, 9, 376.

Larson, P.S., Haagm H.B., \& Silvette, H. Tobacco. Baltimore: Williams \& Wilkings, 1961.

Lin Tsung-yi. A study of the incidence of mental disorder in Chinese and other cultures. Psychiatry, 1953, 16, 313-336.

MacAndrew, C., \& Edgerton, R.B. Drunken comportment: A social explanation. Chicago: Aldine, 1969.

Marcovitz, E. On the nature of addiction to cigarettes. Journal of the American Psychoanalytic Association, 1969, 17, 1074-1096. 
McKennel, A.C. A comparison of two smoking typologies (Research Paper 12). London: Tobacco Research Council, 1973.

Nesbitt, P.D. Smoking, physiological arousal, and emotional response. Journal of Personality and Social Psychology, 1973, 25. 137-145.

Perlick, D. The withdrawal syndrome: Nicotine addiction and the effects of stopping smoking in heavy and light smokers. Unpublished doctorla dissertation, ColumBIA University, 1977.

Schachter, S. Emotion, obesity, and crime. New York: Academic, 1971.

Schachter, S. Nesbitt's paradox. In W.L. Dunn (Ed.), Smoking behavior: Motives and incentives. Washington, D.C.:V. H. Winston, 1973.

Schachter, S. Nicotine regulation in heavy and light smokers. Journal of Experimental Psychology: General, 1977, 106, 5-12.

Schachter, S., Kozlowski, L.T., \& Silverstein, B. Effects of urinary pH on cigarette smoking. Journal of Experimental Psychology: General, 1977, 106, 13-19.

Schachter, S., Silverstein, B., \& Perlick. D. Psychological and pharmacological explanations of smoking under stress. Journal of Experimental Psychology; General, $1977,106,31-40$.

Shapiro, A.K., Shapiro, E.S., Bruun, R.D., \& Sweet, R.D. Gilles de la Tourette syndrome. New York: Raven Press, 1978.

Silverstein, B. An addiction explanation of cigarette-induced relaxation. Unpublished doctoral dissertation, Columbia University, 1976.

Smith, G.M. Personality and smoking: A review of the empirical literature. In W.A. Hunt (Ed.), Learning mechanisms in smoking. Chicago: Aldine, 1970.

Stewart, O. Questions regarding American Indian criminality. Human Organization, 1964, 23, 61-66.

Surgeon General's Report. The health consequences of smoking. Washington, D.C.: U.S. Department of Health, Education and Welfare, 1972.

Tomkins, S.A. modified model of smoking behavior. In E.F. Borgatta \& R.R. Evans (Eds.), Smoking, health and behavior. Chicago: Aldine, 1968.

Wohlfart, G., Ingvar, D.H., \& Hellberg, A.M. Compulsory shouting (Benedek's “Klazomania") associated with oculogyric spasm in chronic epidemic encephalitis. Acta Psychiat. Scand. 1961, 36, 369-377.

Wolff, P. Ethnic differences in alcohol sensitivity. Science, 449-450.

Wolff, P. Vasomotor sensitivity to alcohol in diverse Mongoloid populations. American Journal of Human Genetics, 1973, 25, 193-199. 